\title{
PENGARUH PROGRAM LATIHAN TERHADAP PENINGKATAN KONDISI FISIK ATLET BOLATANGAN PORPROV KUBU RAYA
}

\author{
Edi Purnomo ${ }^{1}$, Urai Gustian ${ }^{2}$, Isti Dwi Puspita ${ }^{3}$ \\ ${ }^{123}$ Program Studi Pendidikan Jasmani, Universitas Tanjungpura, Tanjungpura, Indonesia \\ *edipurnomo22@yahoo.com
}

(Received: March 2019 / Revised: March 2019 / Accepted: March 2019)

\begin{abstract}
ABSTRAK: Tujuan dari penelitian ini adalah untuk mengetahui pengaruh program pelatihan pada peningkatan kondisi fisik atlet bolatangan Porprov Kubu Raya. Penelitian ini menggunakan penelitian kuantitatif yang bertujuan untuk menguji hipotesis dari data yang telah dikumpulkan sesuai dengan teori dan konsep sebelumnya. Penelitian ini termasuk dalam penelitian eksperimental. Populasi yang dimaksud dalam penelitian ini adalah semua atlet bolatangan yang akan turun di PORPROV XII Kalimantan Barat. Sampel yang digunakan dalam penelitian ini adalah semua atlet Bolatangan Universitas, berjumlah 12 atlet. Dari hasil uji $t$ dapat diketahui bahwa Sig $(0,000)<0,05$, hasil ini menunjukkan bahwa HO ditolak yang berarti ada perbedaan yang signifikan antara kondisi fisik pre-test dan post-test atlet bola tangan Kubu Raya sebelum dan setelah diberikan program latihan. Perbedaan ini menunjukkan bahwa program pelatihan meningkatkan kondisi fisik atlet. Besarnya perubahan kondisi atlet handball dapat dilihat dari selisih nilai rata-rata pre test yaitu sebesar 45,49 dengan post test 54,54 . Diketahui bahwa peningkatan kondisi fisik atlet handball Kubu Raya adalah 9,05 atau 19,89\% setelah diberikan program latihan.

KATA KUNCI: Program Latihan, Kondisi Fisik, Bolatangan.
\end{abstract}

ABSTRACTS: AThe purpose of this study was to determine the effect of training programs on improving the physical condition of handball athletes Porprov Kubu Raya. This study uses quantitative research that aims to test the hypothesis of the data that has been collected in accordance with previous theories and concepts. This research was included in experimental research. The population referred to in this study are all handball athletes who will drop in the XII PORPROV of West Kalimantan. The samples used in this study were all of the handball University athletes, numbering 12 athletes. From the results of the $t$ test it can be seen that the Sig $(0,000)<0.05$, this result indicates that $\mathrm{HO}$ is rejected which means there are significant differences between the pre-test and post-test physical condition of Kubu Raya handball athletes before and after being given an exercise program. This difference indicates that the training program improves the athlete's physical condition. The magnitude of the change in the condition of the handball athlete can be seen from the difference in the average value of the pre test that is equal to 45.49 with a post test of 54.54. It is known that the increase in physical condition of Kubu Raya handball athletes was 9.05 or $19.89 \%$ after being given an exercise programe.

KEYWORD:

Exercise Program, Physical Condition, Handball.

\section{PENDAHULUAN}

Setiap atlet harus memiliki kondisi jasmani dan rohani yang sehat sehingga dalam keadaan sehat dapat melakukan segala aktifitas tanpa mengalami hambatan yang cukup berarti. Kondisi fisik yang baik merupakan salah satu unsur pendukung dalam pencapaian yang optimal berbagai macam kegiatan. Prestasi olahraga tidak terlepas dari unsur kondisi fisik. Peningkatan kondisi fisik atlet bertujuan agar kemampuan fisik menjadi prima dan berguna menunjang aktivitas olahraga dalam rangka mencapai prestasi atlet.

Komponen kondisi fisik meliputi kekuatan (strength), kecepatan (speed), daya tahan (endurance), daya ledak otot (muscular explosive power), kelincahan (agility), keseimbangan (balance), kelentukan (flexibility), dan koordinasi (coordination). Semua komponen kondisi fisik 
Journal of Sport and Exercise Science, Vol 2, No 1, 2019 (29-33)

Pengaruh Program Latihan Terhadap Peningkatan Kondisi Fisik Atlet Bolatangan

Porprov Kubu Raya

harus dapat dikembangkan guna menunjang prestasi atlet (Harsono, 2017 : 40). Komponenkomponen kondisi fisik tersebut harus dilatih pada awal pelaksanaan program latihan sebagai pondasi awal dalam mencapai prestasi. Setelah kondisisi fisik terbentuk, maka akan mempermudah pelatih dalam menyusun program latihan selanjutnya yang berkaitan dengan teknik, taktik, dan mental.

Program latihan adalah suatu proses penerapan latihan yang berencana, menurut jadwal, menurut pola dan sistem tertentu, dari yang mudah kesukar, teratur, dari sederhana ke yang lebih komplek yang dilakukan secara berulang-ulang dan kian hari jumlah beban latihannya kian bertambah. Dalam upaya proses latihan yang lebih maksimal sebaiknya pelatih memahami konsep rincian periodisasi dan program latihan, tetapi konsep itu sendiri bukanlah hal yang baru. Itu sudah ada dalam bentuk yang masih kasar untuk waktu yang belum dapat dipastikan kapan itu terjadi. Melalui program latihan yang dirancang dengan baik, pelatih dapat menyusun atau mengatur komponen-komponen latihan yang lebih tepat, dan membantu pelatih didalam menentukan puncak latihan yang tepat pada pertandinganpertandingan yang menjadi sasaran diantara pertandingan utama.

Kabupaten Kubu Raya adalah Kabupaten yang sedang mengembangkan olahraga bola tangan. Dalam perkembangannya olahraga bola tangan akan dipertandingkan dalam even akbar Pekan Olahraga Provinsi (PORPROV) di Kalimantan Barat. Olahraga bola tangan merupakan olahraga yang baru dan pertama kali dipertandingkan pada even (PORPROV) di Kalimantan Barat. Meskipun baru pertama kali, olahraga ini memiliki daya tarik tersendiri. Masyarakat menyambut dengan baik dengan adanya olahraga bola tangan. Hal ini dibuktikan dengan keikutsertaan tiap-tiap tim bola tangan yang mewakili daerahnya dalam even akbar (PORPROV) Kalimantan Barat.
Penjelasan di atas, butuh persiapan yang matang dalam mempersiapkan atlet bola tangan dalam mengikuti kejuaraan (PORPROV). Kondisi fisik, mental, teknik dan strategi harus dipersiapkan dengan baik agar atlet mampu bersaing dalam kejuaraan (PORPROV) di Kalimantan Barat. Berdasarkan survey yang dilakukan penulis masih kurang maksimalnya proses latihan yang diterapkan pada atlet bola tangan. Dari data yang didapatkan kondisi fisik atlet bola tangan Kabupaten Kuburaya itu sendiri sebenarnya masih perlu ditingkatkan, karena belum adanya pemberian materi latihan yang terencana sehingga altet masih melakukan latihan yang biasa-biasa saja.

Pembinaan dan pelatihan atlet bola tangan Kabupaten Kubu Raya sampai saat ini hanya menekankan pada keterampilannya saja. Bahkan untuk atlet yang tergolong masih baru latihannya langsung digembleng dengan latihan keterampilannya. Padahal seharusnya seorang atlet dibentuk untuk memiliki kondisi fisik yang baik dulu agar bisa menerima teknik dan taktik yang diberikan pelatih. Pentingnya kondisi fisik atlet hendaknya dapat segera disadari oleh para pelatih dan juga atlet di Kabupaten Kubu Raya itu sendiri. Pelatih hendaknya dapat selalu mengontrol keadaan kondisi fisik atletnya agar dapat mendeteksi komponen kemampuan fisik apa yang dirasa masih kurang dan perlu adanya perbaikan program latihan.

Berdasarkan penjelasan di atas peneliti berkeinginan melakukan penelitian pada atlet tim bola tangan Kabupaten Kuburaya yang akan melaksanakan (PORPROV) ke 12 di Kalimantan Barat. Adapun objek penelitian yang menjadi bojek penelitian yang akan dilakukan penulis adalah pada penerapan program latihan yang ditujukan dalam pengembangan kondisi fisik atlet. Dengan memfokuskan penelitian pada pengaruh program latihan dapat peningkatan kondisi fisik atlet bola tangan porprov kubu raya. 
Olahraga bola tangan mulai berkembang dengan pesat, hal ini ditandai dengan mulai maraknya diadakan kejuaraan-kejuaraan olahraga bola tangan. Bola tangan adalah olahraga yang memergunakan bola sebagai media utama dan dimainkan menggunakan tangan. (IHF, 2012, 5) mengatakan, Bola tangan (handball) adalah olahraga beregu di mana dua regu dengan masing-masing 7 pemain ( 6 pemain dan 1 penjaga gawang) berusaha memasukkan sebuah bola ke gawang lawan. Permainan ini mirip dengan bola tangan, tapi cara memindahkan bola adalah dengan tangan pemain, bukan kaki. Bola tersebut boleh dilemparkan, atau ditembakkan, permainan ini adalah memasukan bola sebanyak banyaknya kedalam gawang lawan, dan mencegah agar tim lawan tidak dapat memasukkan bola kegawang sendiri. Dalam permainan ini lebih tepat disebut sebagai permainan kombinasi antara permainan basket dan permainan bola tangan, karena keterampilan teknik dasar ketika memainkan bola dengan tangan lebih menyerupai teknik dasar basket yang terdiri dari passing, dribling, shooting.

Dalam teori latihan, disebutkan ada empat aspek latihan yang perlu diperhatikan dan dilatih secara seksama yaitu 1) latihan fisik, 2) latihan teknik, 3) latihan taktik, dan 4) latihan mental. Kondisi fisik merupakan salah satu aspek penting untuk meningkatkan prestasi olahraga, dengan melakukan latihan kondisi fisik memungkinkan siswa untuk dapat mengikuti program latihan dengan baik. Lebih lanjut Harsono (2017:39) menegaskan bahwa perkembangan kondisi fisik yang menyeluruh amatlah penting, oleh karena tanpa kondisi fisik yang baik atlet tidak akan dapat mengikuti latihan-latihan dengan sempurna.

Kondisi fisik merupakan salah satu aspek latihan yang paling dasar untuk dilatih dan di tingkatkan, untuk mendapatkan kondisi fisik yang baik diperlukan persiapan latihan yang dapat meningkatkan dan mengembangkan kondisi fisik, daya tahan merupakan salah satu komponen fisik yang sangat penting untuk dilatih dan ditingkatkan menjadi stamina dalam upaya mencapai prestasi yang optimal. Menurut Marta Dinata (2005:55) daya tahan merupakan kemampuan tubuh untuk melakukan latihan fisik untuk waktu yang lama, hal ini penting dalam olah raga dengan lama waktu melebihi satu menit.

Menurut Dikdik Zafar Sidik, dkk (2007: 1) latihan merupakan proses yang sistematis digunakan untuk menyempurnakan kualitas kinerja olahragawan berupa: kebugaran, keterampilan, dan kapasitas energi dengan memperhatikan aspek pendidikan dan menggunakan pendekatan secara ilmiah..

\section{METODE PENELITIAN}

Penelitian ini termasuk dalam penelitian eksperimen. Penelitian eksperimen merupakan penelitian yang dimaksudkan untuk mengetahui ada tidaknya akibat dari "sesuatu" yang dikenakan pada subjek selidik. Dengan kata lain penelitian eksperimen mencoba meneliti ada tidaknya hubungan sebab akibat Arikunto (2010:207). Sedangkan menurut Consuelo (1993: 93) penelitian eksperimen adalah satu-satunya metode penelitian yang dapat menguji hipotesis mengenai hubungan sebab akibat.

Desain penelitian yang digunakan dalam penelitian ini adalah "One Groups Pretest-Posttest Design", yaitu desain penelitian yang terdapat pretest sebelum diberi perlakuan dan posttest setelah diberi perlakuan. Dengan demikian dapat diketahui lebih akurat, Karena dapat membandingkan dengan diadakan sebelum diberiperlakuan (Sugiyono, 2009: 64).

Dalam suatu penelitian, yang dimaksud populasi adalah wilayah generalisasi yang terdiri atas objek atau subjek yang mempunyai kualitas dan karakteristik tertentu yang ditetapkan oleh peneliti untuk dipelajari dan kemudian ditarik kesimpulannya menurut Arikunto (2010:185). Setelah itu perlu dilakukan pengambilan sampel. Menurut Arikunto (2010:174) Sampel adalah 
Journal of Sport and Exercise Science, Vol 2, No 1, 2019 (29-33)

Pengaruh Program Latihan Terhadap Peningkatan Kondisi Fisik Atlet Bolatangan

Porprov Kubu Raya

sebagian atau wakil populasi yang diteliti. Cara pengambilan sampel dalam penelitian sangatlah penting terlebih jika peneliti ingin hasil penelitiannya berlaku untuk seluruh populasi. Sehingga sampel yang diambil haruslah dapat mewakili semua karakteristik yang terdapat pada populasi jika tidak maka kesimpulan dari penelitiannya akan bias. Adapun sampel yang digunakan dalam penelitian ini adalah keseluruhan atlet bolatangan Kubu Raya yang berjumlah 12 orang atlit.

Suharsimi Arikunto (2013: 136) instrument penelitian adalah alat atau fasilitas yang digunakan peneliti dalam pengumpulan data agar pekerjaannya lebih mudah dan lebih baik. Pengumpulan data dalam penelitian ini adalah dengan tes pengukuran. Instrumen tes yang digunakan untuk pengukuran awal (pretest) maupun pengukuran akhir (posttest) menggunakan tes keterampilan.

Adapun instrumen dalam penelitian ini yaitu (1) Standing Broad Jump digunakan untuk mengukur power tungkai. (2) Tes Kekuatan Otot Lengan (Tes Push Up). (3) Shutle Run (tes kelincahan). (4) Sit Up. (5) Tes kecepatan lari $20 \mathrm{~m}$.

Dari data yang diperoleh dari penelitian ini dilanjutkan dengan mengganalisis data kemudian ditarik kesimpulan dengan menggunakan statistik parametrik. Pengujian hipotesis menggunakan uji$t$ dengan bantuan program SPSS, yaitu membandingkan mean antara kelompok 1 dan kelompok 2. Apabila nilai t hitung lebih kecil dari $t$ tabel, maka Ha ditolak, jika t hitung lebih besar dibanding $t$ tabel maka Ha diterima.

\section{HASIL}

Kegiatan penelitian ini dilaksanakan di kampus Ilmu Keolahragaan Fakultas Keguruan dan Ilmu Pendidikan Universitas Tanjungpura Pontianak pada 3 november 2018. Populasi dalam penelitian ini adalah atlet bola tangan Kabupaten Kubu Raya yanag akan mengikuti Porprov ke XII di
Kalimantan Barat. Sampel dalam penelitian ini diambil secara total sampling keseluruhan yaitu semua atlet bola tangan Kabupaten Kubu Raya yanag akan mengikuti Porprov ke XII di Kalimantan Barat yang berjumlah 12 orang..

Tabel 1. Hasil Perhitungan Uji Hipotesis Data Penelitian

\begin{tabular}{|c|c|c|c|}
\hline & $\mathrm{N}$ & correlation & Sig. \\
\hline Pair 1 & 12 & .949 & .000 \\
\hline
\end{tabular}

Dari hasil uji $t$ dapat dilihat bahwa nilai Sig $(0,000)<0,05$, hasil ini menunjukkan bahwa $\mathrm{HO}$ ditolak yang berarti terdapat perbedaan yang signifikan antara pre-test dan post-test kondisi fisik atlet bola tangan Kubu Raya sebelum dan sesudah diberikan program latihan. Adanya perbedaan ini menunjukkan bahwa program latihan meningkatkan kondisi fisik atlet. Besarnya perubahan kondisi atlet bola tangan tersebut dapat dilihat dari perbedaan nilai rata-rata pre tes yaitu sebesar 45.49 dengan pos-test sebesar 54.54. Secara spesifik hasil perlakuan dapat diketahui melalui penghitungan perbedaan ratarata dan rata-rata pre-test, hasil presentase peningkatanya sebagai berikut :

Tabel 2. Hasil PerbandinganRata-rata Peningkatan Kondisi Fisik

\begin{tabular}{lll}
\hline \multicolumn{2}{l}{ Rata-rata Post Tes } \\
Peningkatan & $\%$ & Rata-rata Pre tes \\
& & \\
\hline 54.54 & & 45.49 \\
9.05 & 19.89 & \\
\hline
\end{tabular}

Berdasarkan tabel tersebut dapat diketahui bahwa peningkatan kondisi fisik atlet bola tangan Kubu Raya sebesar 9,05 atau 19.89 \% setelah diberikan program latihan. Melihat peningkatan data tersebut terjadi peningkatan yang signifikan pengaruh program latiahan terhadap peningkatan kondisi fisik athlet bola tangan porprov kubu raya 


\section{PEMBAHASAN}

Berdasarkan hasil uji statistik sample T-test pada tabel 2 dapat disimpulkan bahwa program latihan berpengaruh terhadap peningkatan kondisi fisik atlet bola tangan Kuburaya. Dari hasil uji $t$ dapat dilihat bahwa nilai Sig $(0,00)<0,05$, hasil ini menunjukkan bahwa $\mathrm{HO}$ ditolak yang berarti terdapat perbedaan yang signifikan antara pre-test dan post-test kondisi fisik atlet bola tangan Kubu Raya sebelum dan sesudah diberikan program latihan. Adanya perbedaan ini menunjukkan bahwa program latihan meningkatkan kondisi fisik atlet. Besarnya perubahan kondisi atlet bola tangan tersebut dapat dilihat dari perbedaan nilai rata-rata pre tes yaitu sebesar 45.49 dengan pos-test sebesar 54.54. Dengan demikian diketahui bahwa peningkatan kondisi fisik atlet bola tangan Kubu Raya sebesar 9,05 atau $19.89 \%$ setelah diberikan program latihan.

\section{SIMPULAN DAN REKOMENDASI}

Berdasarkan hasil penelitian di atas maka dapat ditarik kesimpulan terdapat pengaruh program latihan terhadap peningkatan kondisi fisik atlet bola tangan Kabupaten Kubu Raya. Perbedaan nilai rata-rata pre tes yaitu sebesar 45.49 dengan pos-test sebesar 54.54. Dengan demikian diketahui bahwa peningkatan kondisi fisik atlet bola tangan Kubu Raya sebesar 9,05 atau $19.89 \%$ setelah diberikan program latihan.

Berdasarkan kesimpulan di atas, seperti yang telah dikemukakan maka dapat disarankan dengan beberapa saran sebagai berikut: (1) Hasil penelitian ini dapat memberikan informasi tentang manfaat program latihan dalam peningkatan kondisi fisik atlet sehingga diharapkan para pelatih dapat menerapkan hal yang serupa dalam melakukan latihan. (2) Hasil penelitian ini dapat menjadi acuan bagi peneliti berikutnya. Diharapkan peneliti lain dapat menambah jumlah responden, jenis penelitian, dan menambah variabel penelitian yang berhubungan dengan kondisi fisik sehingga diharapkan diperoleh hasil penelitian yang lebih mendalam dan variatif.

\section{REFERENSI}

Agus mahendra. 2000. Bola Tangan. Jakarta: Depdiknas

Consuelo dkk. 1993. Pengantar Metode Penelitian. Jakarta: UI-Press.

Harsono, (2017). Kepelatihan Olahraga, Teori dan Metodologi. Edisi kedua. Bandung: Tambak. PT Remaja Rosdakarya Offset.

IHF. (2012). International handball federation. rules of the game. Basel Switszerland.

Marta Dinata. 2005. Rahasia Latihan Sang Juara Menuju Prestasi Dunia. Jakarta: Penerbit Cerdas Jaya.

Moustafa, H. (2010). Teaching handball at School. introduction to handball for student aged 5 to 11. Handbook. International Handball Federation. (IHF).

Rachman, H. A. \& Susanto, E. (2005). Bolatangan, sebuah pengantar dalam pembelajaran. Universitas Negeri Yogyakarta

Sugiyono, 2009. Metode Penelitian, Bandung: CV Alfa Beta.

Sajoto. 2010. Peningkatan dan Pembinaan Kekuatan kondisi fisik. Semarang: Effhar dan Dahara Prize.

Suharsimi Arikunto. 2013, Prosedur Penelitian Suatu Pendekatan Praktik, Jakarta: Rineka Cipta,

Zafar Sidik, Dikdik. (2010) Pembinaan Kondisi Fisik (Dasar dan Lanjutan). Bandung. FPOK UPI 